\title{
SYNOVIAL RUPTURE OF THE ELBOW JOINT
}

\author{
BY \\ J. D. GOODE \\ Rheumatism Research Wing, Department of Experimental Pathology, University of Birmingham
}

Acute synovial rupture in rheumatoid arthritis was first described by Dixon and Grant (1964). Five of six patients developed rupture at the knee joint. Typically pain suddenly occurred behind the knee and radiated into the calf. The effusion lessened or disappeared and caused painful swelling of the calf mimicking deep vein thrombosis. One patient developed indurated tender oedema of the hand and forearm associated with disappearance of an extensor sheath effusion.

Further reports have been confined to synovial rupture at the knee. Tait, Bach, and Dixon (1965) reported five cases, and showed the value of arthrography in confirming the diagnosis. Hall and Scott (1966) described four examples as well as three cases of chronic calf cysts, two of which formed after acute episodes. The diagnosis of synovial rupture is easily missed and occurs in joints other than the knee. This paper reports its occurrence at the elbow joint in six patients with rheumatoid arthritis.

\section{Material and Methods}

Six patients with classical or definite rheumatoid arthritis (Ropes, Bennett, Cobb, Jacox, and Jessar, 1959) were studied (see Table I). The affected elbows showed flexion contractures of $30^{\circ}$ or more, and a definite effusion was present in all but one patient.

\section{Elbow Arthrography}

Aspiration of the elbow joint was attempted by a lateral approach immediately posterior and proximal to the head of the radius with the forearm pronated and perpendicular to the upper arm using a No. 1 disposable needle. If no fluid was aspirated the needle was positioned radiologically before injecting slowly 4 to $10 \mathrm{ml}$. of contrast medium (either "Conray" 420 or "Urografin" 60 per cent.). Normal elbow arthrograms are shown in Figs 1 and 2 (opposite). To encourage movement of contrast material out of the joint if rupture was present, the patient moved the elbow repeatedly before the films were taken, but strenuous movement was avoided.

\section{Venography}

This was performed in only one patient. A dorsal hand vein was cannulated against the direction of flow and Hypaque was injected.

\section{Arm Volumes}

Serial arm volumes (Case 3) were measured, using the method of Theobald and Lundborg (1963).

\section{Clinical and Arthrographic Findings}

All patients showed swelling extending from the elbow into the forearm. When severe it spread to the hand and into the upper arm. Most cases showed pitting oedema of all forearm soft tissue, but sometimes only the muscle pitted on pressure.

TABLE I

RESULTS IN SIX PATIENTS

\begin{tabular}{c|c|c|c|c|c|c|c}
\hline & Sex & $\begin{array}{c}\text { Age } \\
\text { (yrs) }\end{array}$ & $\begin{array}{c}\text { Duration of } \\
\text { Disease } \\
\text { (yrs) }\end{array}$ & $\begin{array}{c}\text { Sheep } \\
\text { Cell } \\
\text { Agglutination } \\
\text { Test }\end{array}$ & $\begin{array}{c}\text { Erythrocyte } \\
\text { Sedimentation } \\
\text { Rate } \\
\text { (mm./1 hr.) }\end{array}$ & $\begin{array}{c}\text { Treatment } \\
\text { Changes on Plain } \\
x \text { rays of Elbow }\end{array}$ \\
\hline 1 & M & 53 & 21 & Negative & Severe & Betamethasone \\
Indomethacin \\
Indomethacin \\
Soluble aspirin \\
Prednisone \\
Indomethacin \\
In
\end{tabular}


Where the rupture occurred or worsened rapidly it caused pain in the forearm, and often local erythema. Peau d'orange was not uncommon, and small vesicles were seen in one patient. The pain of the acute ruptures worsened rather than improved with use of the limb. With the arm resting in a sling the pain and swelling would lessen in a few days. Although all were right-handed, the left elbow was troubled as often as the right. One had both elbows affected. Leakage of contrast material always occurred into the forearm and never proximally. In two the leakage was from the medial aspect of the joint and gave a wavy linear appearance.

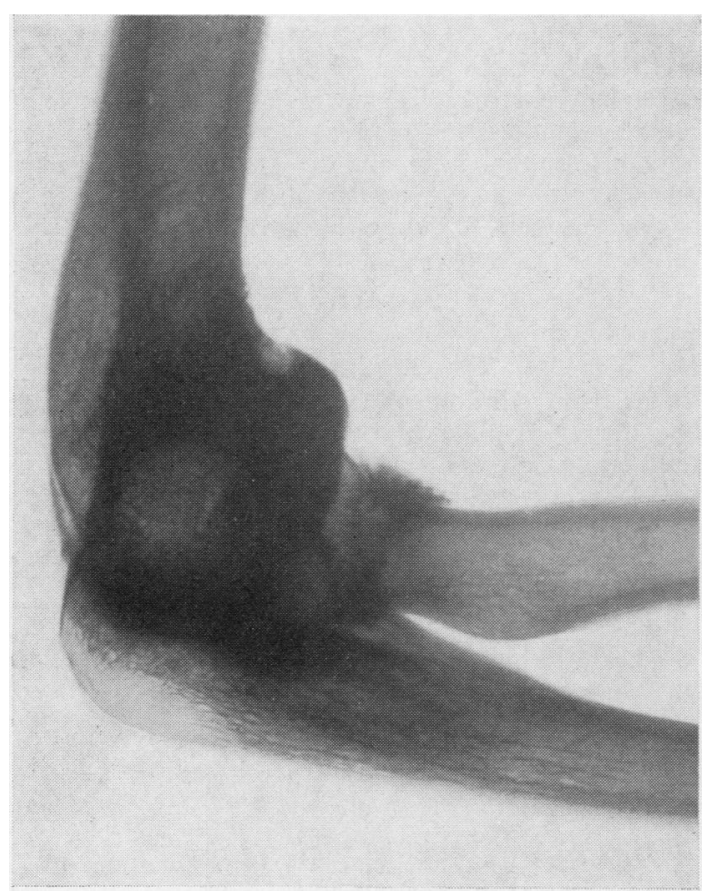

In two the leakage was from the lateral aspect and the appearance more diffuse. The first arthrogram in Case 3 and the only one in Case 4 showed no leakage of contrast material from the joint.

\section{Discussion}

Six patients were seen with this condition during 14 months when about 140 patients with rheumatoid arthritis were seen personally, which suggests that it is not uncommon. It occurred at all stages of disease from the onset of symptoms (Case 5) to cases of long standing (Cases 1 and 3), but all of these patients were only moderately restricted in the use of their upper limbs, or were active at work or in the home. That the condition can be bilateral (Case 6) should not cause surprise, as symmetry is a feature of rheumatoid arthritis, and if one limb deteriorates in function the other is used more.

There have been no large single cysts spreading into the distal muscle mass as occurs in the calf. This may be explained by the small volume of fluid in effusions at the elbow joint, pernaps 1 to $10 \mathrm{ml}$. compared with 10 to $100 \mathrm{ml}$. or more at the knee, and may also be due to greater opportunity to spread between many muscles in the forearm.

In some patients it was easier to pit the forearm muscles on pressure than the skin. This suggests that the spread of joint fluid may be largely contained within the fascial compartment of the forearm. Stab or puncture wounds of the upper extremity especially of the volar aspect of the forearm may produce an expanding subfascial haematoma with signs of nerve compression (Bennett, 1965). A similar though less acute mechanism from leakage of joint fluid may have been the cause of ulnar paraesthesiae in one patient (Case 3) which worsened on using the limb.

The arthrogram of one patient (Case 3) was negative initially, though positive a year later. Leakage of synovial fluid may be intermittent, or

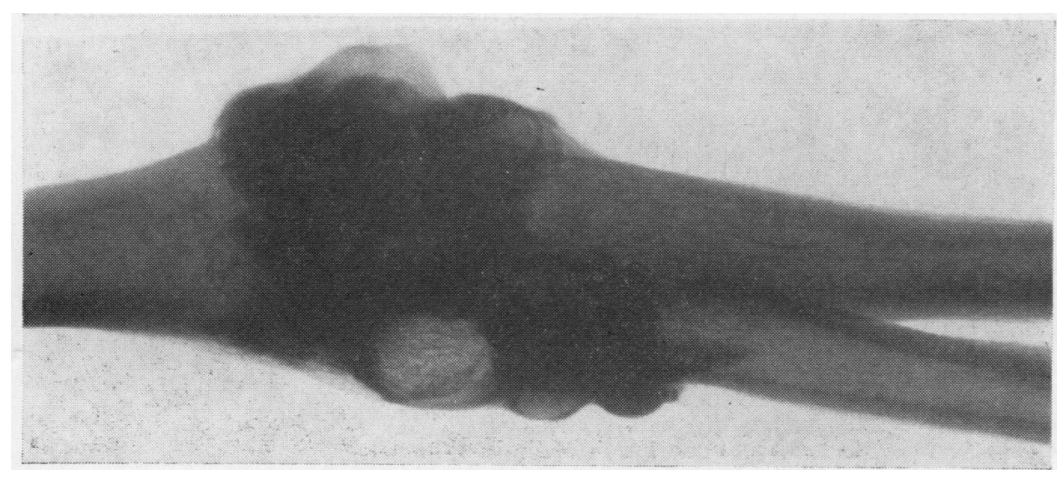

Figs 1 and 2.--Normal post mortem arthrograms of elbow. 
at times so slight that it will not show radiologically. The only arthrogram of another patient (Case 4) was also negative, but this did not exclude the diagnosis, as the clinical features were characteristic.

Localized areas of pitting oedema may occur around joints in rheumatoid arthritis and some may be due to small localized synovial ruptures. Dixon and Grant (1964) showed that, if plasma was used to distend a knee joint, experimental rupture did not cause calf inflammation as did rupture of the synovial membrane in rheumatoid arthritis. Freshly aspirated rheumatoid synovial fluid injected into the patient's own skin caused inflammation in 20 per cent. of cases (Duthie, 1964); a localized area of erythema which occurred in Case 1 may be a clinical example of this.

The clinical picture of synovial rupture of the elbow joint in rheumatoid arthritis appears to be slightly different from that in the knee. Perhaps at other joints it may differ more. Widespread small leaks of synovial fluid may be important in maintaining intra-articular and peri-articular inflammatory changes in many joints in rheumatoid arthritis, and explain the adverse effect of exercise, and the beneficial effect of rest and paralysis on rheumatoid joints.

\section{Summary}

Synovial rupture at the elbow is described in six patients with rheumatoid arthritis. All had oedema of the elbow and forearm, and the swelling might spread to the hand and upper arm, causing pain and often erythema. Arthrograms in four patients showed leakage of contrast medium from the joint into the forearm.

I wish to thank Dr. C. F. Hawkins for allowing me to investigate his patients, and for much encouragement and advice in preparing this paper. I should also like to thank Dr. A. St. J. Dixon for advice, Dr. P. S. O'Sullivan for taking the venogram, and the Arthritis and Rheumatism Council for the award of a Fellowship which enabled this work to be carried out.

\section{APPENDIX}

\section{Clinical and Radiogical Observations}

Case 1. A man aged 53 had pain and swelling of the left forearm for 2 weeks which worsened by each evening though never disturbed his sleep. Swelling was most marked on the inner side with pitting oedema extending to the dorsum of the hand. An arthrogram showed a linear leakage of contrast material into the forearm medially.

4 months later pain and swelling returned fairly suddenly and worsened during the following morning. That day the elbow effusion was tense, and on the inner side about $6 \mathrm{~cm}$. below the joint there was a well-demarcated raised erythematous area beneath which most pain was felt. The repeat arthrogram (Fig. 3) was like the first, except that contrast material formed a small pool directly beneath the site of erythema and maximal pain. The synovial fluid was sterile.

Case 2. A 65-year-old woman had more pain in the right elbow, which showed a small effusion with local

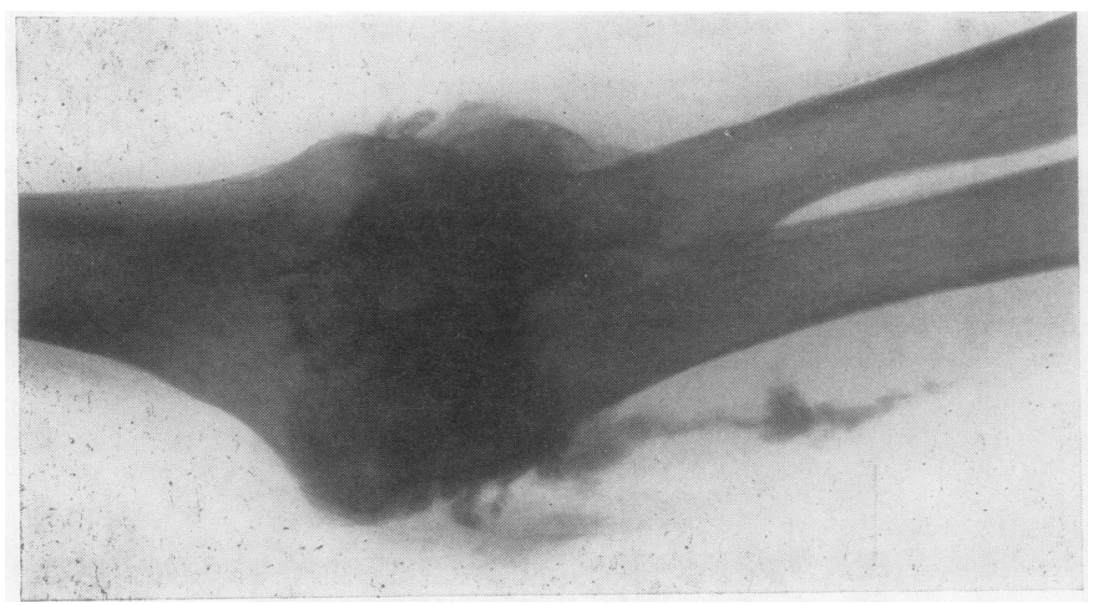

Fig. 3.-Arthrogram confirming a second acute synovial rupture

(Case 1). The small pool of contrast material in the forearm lay directly beneath localized skin erythema and the site of pain. 
pitting oedema and erythema most marked on the lateral side. An arthrogram showed contrast material leaking from the joint laterally and posteriorly as a diffuse band (Fig. 4).

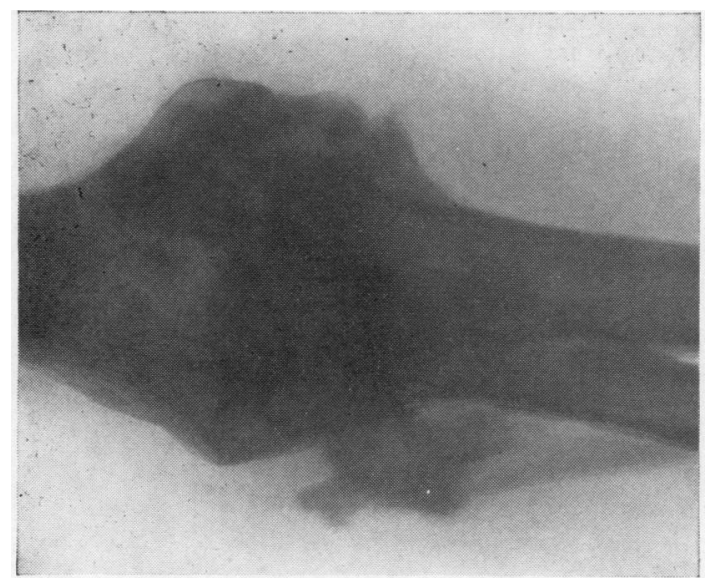

Fig. 4.-Arthrogram confirming synovial rupture in a woman with chronic forearm swelling and erythema (Case 2).

5 weeks later pain on movement worsened in the right elbow. After 2 days the forearm became swollen followed by the hand. The swelling partly subsided each night, but by the next evening it would be worse with patchy erythema and a burning sensation. Pitting oedema was present from the middle of the right upper arm to the fingers. As the oedema lessened with rest small vesicles came up over the back of the elbow. Soon afterwards the patient was able to use the arm normally, and the oedema of the right forearm was limited to a small area medial and distal to the elbow.

Case 3. Rheumatoid arthritis had been diagnosed in 1944 in a woman then aged 29 during her only pregnancy. There was a possible rupture of the right elbow joint in 1951. Subsequently the joint condition fluctuated without permanent crippling until 1964, when pain and instability of the left knee severely limited walking.

In the summer of 1966 the patient noticed painless swelling of the left forearm which initially worsened. It had lessened slightly when she was first seen in November, 1966. An arthrogram of the left elbow then showed many small sacculations of the joint space but not synovial rupture.

During the following summer tingling of the little finger and occasionally of the adjacent part of the ring finger developed. Using her hand aggravated this. In December, 1967, there was pitting oedema of the arm from just above the elbow down to the wrist. The slight erythema noticed on the ulnar side a year before had gone.

A venogram of the left arm was normal. It showed deflection of veins near the elbow but no compression. Flow was good. $5 \mathrm{ml}$. Urografin and prednisolone trimethyl acetate were injected into the left elbow joint. Screening showed no leakage of contrast material but at 15 minutes films showed a single linear leakage medially (Fig. 5). The arm was rested in a sling, and by the next day the forearm swelling had decreased and the numbness of the little finger gone. Volume measurements of the forearm and hand (Table II) confirmed the clinical findings.

TABLE II

VOLUME MEASUREMENTS OF FOREARM AND HAND IN CASE 3

\begin{tabular}{|c|c|c|c|}
\hline \multirow{2}{*}{\multicolumn{2}{|c|}{ Time of Reading }} & \multicolumn{2}{|c|}{ Arm Volume (ml.) } \\
\hline & & Readings & Mean \\
\hline $\begin{array}{l}\text { Day of arthrogram } \\
\text { (before this and } \\
\text { steroid injection) }\end{array}$ & $\left\{\begin{array}{l}13.00 \mathrm{hrs} \\
14.00 \mathrm{hrs}\end{array}\right.$ & $\begin{array}{l}1,504 \\
1,500\end{array}$ & 1,502 \\
\hline 5 days later & Noon & $\begin{array}{l}1,399 \\
1,433\end{array}$ & 1,416 \\
\hline 13 days later & $10.00 \mathrm{hrs}$ & $\begin{array}{l}1,420 \\
1,427 \\
1,430\end{array}$ & 1,426 \\
\hline
\end{tabular}

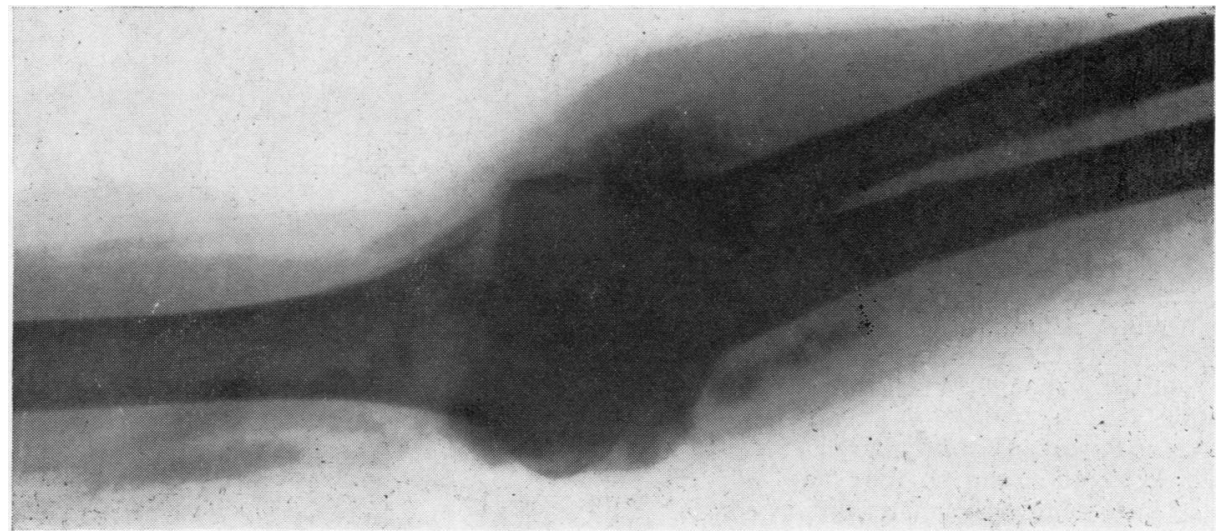

Fig. 5.-Arthrogram of the elbow of a woman with long-standing painless swelling of the forearm (Case 3 ). 
Case 4. A woman aged 33 denied pain or swelling of the forearms. The left elbow appeared normal, but the right showed swelling of the medial aspect with pitting oedema of the deeper tissues, which were only slightly tender. 4 weeks later the patient had become aware of swelling around and below the right elbow, and there was pitting oedema of the whole right forearm although at the wrist it was slight. Peau d'orange was present near the elbow, but no erythema. An arthrogram showed several pouches extending anteriorly, but no leakage of contrast material.

Case 5. A woman aged 36 had had swelling of the left forearm for 2 weeks at the onset of arthritis 2 years before. In the last 10 months the left elbow had been swollen and painful and she had four further episodes of painful swelling of the left forearm lasting from 2 days to 2 weeks. Although no episode has yet been observed and no arthrogram done a (retrospective) diagnosis of ruptured joint was considered likely.
Case 6. Rheumatoid arthritis had begun 12 years before in a man then aged 49 , and after 3 years had forced him to cease work as a builder's labourer. He then found employment operating a non-automatic lift. He had since had 2 weeks of severe swelling of the left forearm which extended to the hand and upper arm, and less severe episodes of swelling had recurred after that.

The right elbow showed local oedema, erythema, peau d'orange, and possibly an effusion. The left showed a definite effusion with a cystic swelling on the radial side, with oedema which was most marked laterally. It was easier to pit the underlying muscle on pressure than the skin. An arthrogram of the left elbow showed a large protrusion of the joint radially and many smaller pouches elsewhere. Some showed small filling defects. On the posterior and medial aspect of the joint, illdefined irregular and mainly linear opacities extended 4 $\mathrm{cm}$. into the forearm (Fig. 6).

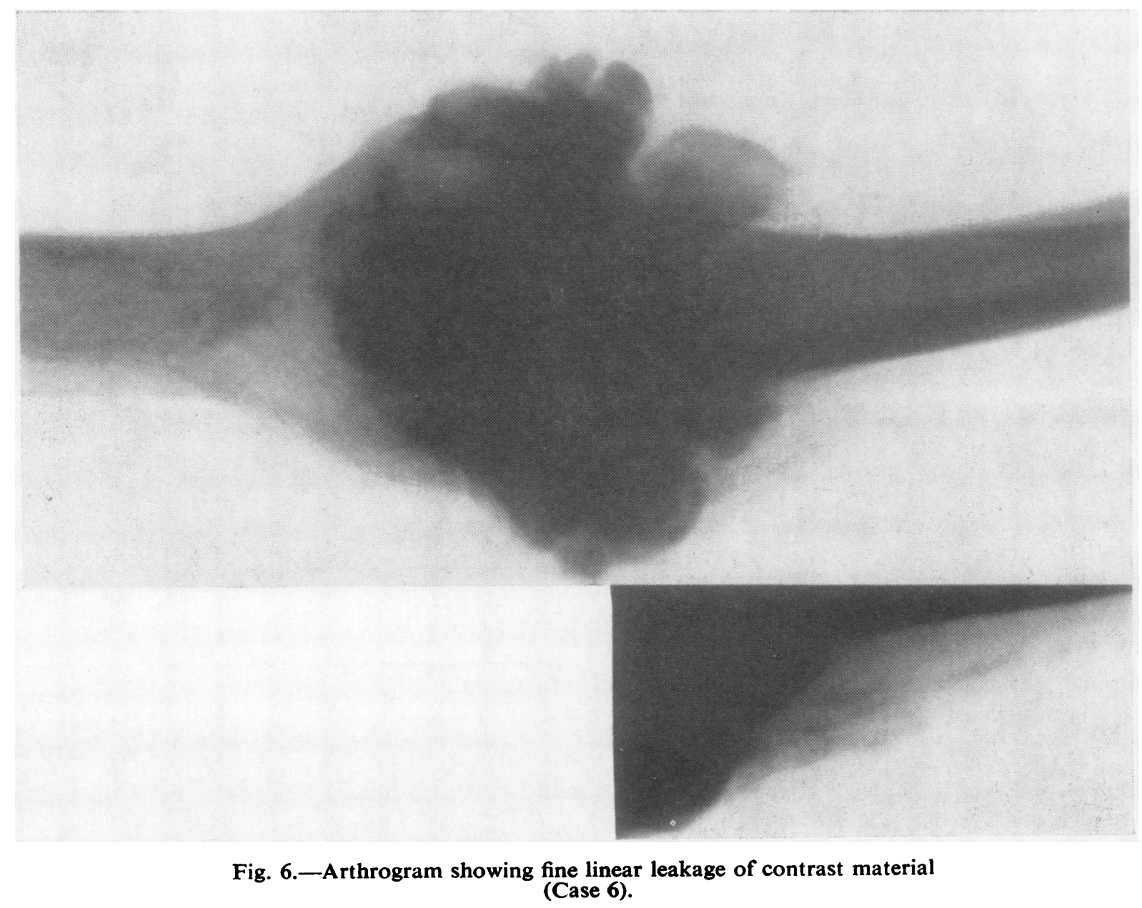

\section{REFERENCES}

Bennett, J. E. (1965). Plast. reconstr. Surg., 36, 622 (Expanding forearm haematoma after apparent minor injury).

Dixon, A. St. J., and Grant, C. (1964). Lancet, 1, 742 (Acute synovial rupture in rheumatoid arthritis. Clinical and experimental observations. 6 cases).

Duthie, J. J. R. (1964). In "Symposium: Polyarthritis, Edinburgh, 1963", p. 74. Royal College of Physicians of Edinburgh.

Hall, A. P., and Scott, J. T. (1966). Ann. rheum. Dis., 25, 32 (Synovial cysts and rupture of the knee joint in rheumatoid arthritis).

Ropes, M. W., Bennett, G. A., Cobb, S., Jacox, R., and Jessar, R. A. (1959). Ibid., 18, 49 (Diagnostic criteria for rheumatoid arthritis, 1958 Revision). 
Tait, G. B. W., Bach, F., and Dixon, A. St. J. (1965). Ibid., 24, 273 (Acute synovial rupture. Further observations).

Theobald, G. W., and Lundborg, R. A. (1963). J. Obstet, Gynaec. Brit. Cwlth, 70, 408 (Changes in limb volume and in venous infusion pressures caused by pregnancy).

\section{Rupture synoviale de l'articulation du coude}

\section{RÉSUMÉ}

On décrit la rupture synoviale au niveau du coude chez six patients atteints de polyarthrite rhumatoïde. L'oedème du coude et de l'avant-bras est toujours présent et la tuméfaction peut s'étendre à la main et au bras occasionant une douleur et souvent un érythème. Des arthrogrammes chez quatre malades révélèrent une fuite du milieu de contraste de l'articulation à l'avant bras.

\section{Rotura sinovial de la articulación del codo}

\section{SUMARIO}

Se describe la rotura sinovial en el codo en seis enfermos con poliartritis reumatoide. El edema del codo y del antebrazo es siempre presente y la hinchazón puede extenderse hacia la mano y el brazo, causando dolor y, a menudo, eritema. Artrogramas en cuatro enfermos revelaron un escape del medio de contraste de la articulación al antebrazo. 